\title{
Escrevivências': o blog e o microblog como espaços de pesquisa em históría de vida
}

Roselete Fagundes de Aviz

Professora do Departamento de Metodologia de Ensino (MEN/CED) da Universidade Federal de Santa Catarina (UFSC), pesquisadora do Núcleo Infância, Comunicação, Cultura e Arte (NICA-UFSC).

E-mail: roseaviz@hotmail.com

\section{Gilka Elvira Ponzi Girardello}

Professora do MEN/CED da UFSC, pesquisadora do NICA-UFSC.

E-mail: gilkagirardello@gmail.com

Resumo: A pesquisa que serviu de base para este trabalho teve como objetivo contribuir com o conhecimento e com o diagnóstico das formas de violências em contextos de fundamentalismos religiosos, aprofundando as discussões teóricas sobre o assunto, tendo sempre em vista possibilidades de debates sobre o papel que a Educação tem nesse estudo. A metodologia pautou-se na definição de uma coleta de base por meio de um blog, representada pelas histórias de vida de meninas e mulheres que sofreram algum tipo de violência em contextos de fundamentalismos religiosos. Entre os resultados obtidos, concluiu-se que, para pesquisar temáticas ainda envoltas em silenciamentos e preconceitos, como é o caso da relação entre violência de gênero e fundamentalismos religiosos, aliar o blog a outras ferramentas da cibercultura pode ser de grande relevância, uma vez que isso suscita o debate e permite a criação de espaços de confiança e intimidade que favorecem a partilha de depoimentos pessoais.

Palavras-chave: blog; twitter; ferramentas digitais de pesquisa; história de vida; fundamentalismos religiosos.
Abstract: This article is based on a research aimed at contributing to the knowledge and diagnosis of forms of violence in contexts of religious fundamentalisms, and to deepen the theoretical discussions of the subject, with a special focus on the role played by Education. The methodology included the creation of a weblog opened to the postings of life histories of girls and women who suffered violence in contexts of religious fundamentalisms. The analysis concluded that, in order to study themes still involved in silence and prejudice, as is the case of the relationship between gender violence and religious fundamentalisms, combining the blog with other tools of cyberculture can be of great relevance, since that it allows for the creation of spaces of trust and intimacy that favor the sharing of personal testimonies.

Keywords: blog; twitter; digital research tools; life history; religious fundamentalism.
1. No sentido de Conceição Evaristo. "Escrevivências: escrever, viver, se ver" (EVARISTO, 2011, p. 10).

2. Este texto foi apresentado oralmente na $39^{\mathrm{a}}$ Reunião da Anped, realizada de 20 a 24 de outubro de 2019.

Recebido:11/05/2020

Aprovado:02/09/2020 


\section{comunicação \& educação • Ano XXVI • número 1 • jan/jun 2021}

\section{INTRODUÇÃO}

O presente artigo busca refletir sobre alguns aspectos principais da pesquisa de pós-doutorado que conduzimos entre 2017 e 2018 sobre fundamentalismos religiosos contra meninas e mulheres, com ênfase na aculturação, nas violências e no papel da educação. O objetivo é discutir contribuições metodológicas desse estudo, especialmente nos aspectos alusivos aos objetos blog e microblog (Twitter) como espaços de pesquisa associados ao método Histórias de Vida.

A pesquisa teve como corpus histórias de vida - orais e escritas - de meninas e mulheres que sofreram algum tipo de violência em contextos religiosos brasileiros. Os relatos orais foram gravados presencialmente em áudio, enquanto os escritos foram enviados para um e-mail disponibilizado especialmente para receber depoimentos a serem publicados no blog criado no âmbito da pesquisa. Fragmentos dessas histórias foram publicados no blog, o qual se constituiu também como um excelente instrumento de reflexão sobre a temática da violência contra meninas $e$ mulheres nos contextos religiosos. A temática foi também colocada em debate no Twitter.

Situamos o conceito de fundamentalismo religioso no contexto da Modernidade, entendida por Boaventura de Sousa Santos como representação de um movimento histórico, cultural e social, surgido a partir do século XVI, marcado pela elevação da categoria de mercado a principal motivadora das relações de poder ${ }^{3}$. A esse respeito, Karen Armstrong, ao analisar os movimentos fundamentalistas que se desenvolveram em três religiões monoteístas - judaísmo, cristianismo e islamismo expressa um dos conceitos de fundamentalismos religiosos do seguinte modo:

São formas de espiritualidade combativas, que surgiram como reação a alguma crise. Enfrentam inimigos cujas políticas e crenças secularistas parecem contrárias à religião. Os fundamentalistas não veem essa luta como uma batalha política convencional, e sim como uma guerra cósmica entre as forças do bem e do mal. Temem a aniquilação e procuram fortificar sua identidade sitiada através do resgate de certas doutrinas e práticas do passado. Para evitar contaminação, geralmente se afastam da sociedade e criam uma contracultura; não são, porém, sonhadores utopistas. Absorveram o racionalismo pragmático da modernidade e, sob a orientação de seus líderes carismáticos, refinam o "fundamental" a fim de elaborar uma ideologia que fornece aos fiéis um plano de ação. Acabam lutando e tentando ressacralizar um mundo cada vez mais céptico ${ }^{5}$.

Para examinar as implicações desse movimento contra a cultura científica e secular nascida no Ocidente, nossa pesquisa procurou mostrar como esses deslocamentos, que estão entre os mais influentes por surgirem de medos, ansiedades e desejos comuns, geram violências e opressões de dimensões incomensuráveis, especialmente sobre mulheres e crianças.

Desse modo, a pesquisa procurou iluminar a relação entre a violência em contextos de fundamentalismos religiosos contra crianças, mais especificamente contra meninas, e o papel da educação nesse assunto, porque entendemos que esta, de certo modo, em virtude de uma ênfase na tolerância ${ }^{6}$, tem negligenciado as manifestações de violências que advêm desses contextos. 
As violências concebidas e/ou praticadas no tecido social podem interferir nas relações educativas. Tais violências, muitas vezes oriundas de contextos fundamentalistas religiosos, podem ser castigos físicos, maus-tratos, abuso sexual e silenciamentos, que são, por sua vez, produtores de fracassos na aprendizagem, evasão, repetência, isolamento ou distúrbios de atenção. Tais processos, que nem sempre deixam marcas visíveis, são muitas vezes negligenciados pela escola em nome do discurso da tolerância. No entanto, podem gerar conflitos na vida das crianças e adulterar sua infância, em dimensões corporais, afetivas e cognitivas.

A pesquisa deu ainda mais consistência a essas ideias quando nos permitiu perceber a escola como (re)produtora do medo, assim como o são os contextos fundamentalistas religiosos. No caso específico da violência contra crianças, o medo pode servir como uma "gramática" que ensina as crianças e os adolescentes a manterem um pacto de silêncio para não expor, não "agredir" quem os violenta.

Sobre o medo, o trabalho da norte-americana Marlene Winell ${ }^{7}$ trouxe grande contribuição à pesquisa. A autora ampliou o debate sobre o tema ao colocar nele o abuso espiritual como categoria maior, uma vez que funciona como um termo guarda-chuva que agrega todas as outras formas de abuso, inclusive o sexual. Segundo a autora, a compreensão do abuso espiritual somente dá-se no campo da compreensão dos aspectos do fundamentalismo que são mentalmente e emocionalmente manipulativos. Nessa perspectiva, o medo aparece como um dos mais potentes modos de manipulação.

No contexto da pesquisa, as histórias de vida foram escolhidas como perspectiva metodológica por seu potencial de conferir às mulheres vítimas de violência um sentido ativista, de luta contra as injustiças. Vemos, assim, alguns indicativos para nossa compreensão de que o uso do blog e do microblog como dispositivos de pesquisa criou um lugar da voz para essas mulheres, no sentido de que pudessem "contar a todo mundo" o que acontece em sua intimidade, indo ao encontro de outras vozes que a elas afinam-se. Na perspectiva feminista em que contextualizamos o conceito de histórias de vida, podemos pensar que essas podem ser uma arma de resistência das mulheres, uma alternativa à história do processo de colonização, à geopolítica eurocêntrica que estabeleceu paradigmas epistemológicos, políticos, ontológicos e religiosos como verdades universais, promovendo uma fortaleza de invisibilidades e silenciamentos, que se manifesta de modo particular entre as mulheres.

Dessa forma, o blog e o microblog, na postagem de textos em diferentes linguagens, como a literatura, a música, a fotografia, além da classificação por tags, abrem a temática para diferentes debates - ligados a gênero, sexo, etnia, religião, classe, feminismo, subalternidade, dentre outros. Servem, assim, de suporte, ambiente, multiplicação de autoria e propulsão de pesquisas que associam a investigação feminista às histórias de vida. Além disso, o blog, aliado ao microblog, certifica a cobertura da pesquisa, possibilita a criação do desenho do estudo, bem como proporciona o encontro e o debate entre pessoas que também se interessam pela mesma temática.

7. WINELL, Marlene. Leaving the Fold: a guide for former fundamentalists and others leaving their religion. Berkely, CA: New Harbinger Publications, 2007. 


\section{PERCURSOS DE INVESTIGAÇÃO POR MEIO DE HISTÓRIAS DE VIDA}

A investigação que sustenta este texto tem como base a realização de Histórias de Vida. No estudo, o objetivo era escutar, dar a conhecer e compartilhar as vozes de mulheres que sofreram/sofrem algum tipo de violência em contextos religiosos, para que, a partir do discurso produzido pelas mulheres biografadas, suas subjetividades e singularidades, fosse possível atribuir significados e sentidos aos fenômenos, bem como produzir conhecimento científico. Inscrito no quadro da metodologia qualitativa, o método biográfico utilizado centrou-se, especialmente, na recolha e análise de histórias de vida. Segundo Magalhães ${ }^{8}$, os métodos biográficos contribuem com "um modo feminista de fazer ciência", tendo dois grandes objetivos: "criticar, denunciar e produzir alternativas aos pressupostos androcêntricos; e mudar as formas de interpretar, apreciar e compreender as vidas das mulheres, através da experiência histórica”. Para autora, "nomear vidas silenciadas" é "dar voz aos/às que foram deixados/ as de fora da história”.

Assim, enquanto procedimento epistemológico, as histórias de vida materializam vozes de pessoas individuais, sobretudo pertencentes a grupos sociais a quem a história silenciou. As histórias de vida apoiam-se na produção de conhecimento por meio da intersubjetividade, ou seja, em que cada pessoa partilha conosco a sua forma de ver o mundo, a partir de seu lugar de fala e posição social. Ao/à investigador/a cabe, nessa perspectiva feminista, não apenas fazer a recolha de histórias de vida, mas trazer a voz fidedigna dessas pessoas, suas expressões e visões de mundo, uma vez que é nesse aspecto que se consegue confrontar o silêncio que a história e a produção científica dominante têm imposto ${ }^{9}$. Magalhães inscreve o percurso da pesquisa em história de vida na procura do sujeito político mulher e da agência feminista no campo da Educação. Nesse sentido, a autora defende que as histórias sejam contadas "pela própria voz”, ou seja, sem questões dirigidas, especificamente, à temática.

Nesse aspecto, consideramos importante dizer que, no processo da pesquisa, conhecendo a perspectiva do método sobre histórias de vida defendida por Magalhães, mudamos nossa abordagem metodológica de pesquisa em Histórias de Vida. Na recolha das primeiras histórias, apenas nos preocupamos em focar questões específicas sobre a problemática da pesquisa. No blog, por exemplo,

8. MAGALHÃES, Maria José. Construção do sujeito mulheres: subjetividades das vozes e dos silêncios. In: MAGALHÃES, Maria José et al. (org.). Pelo fio se vai à meada: percursos de investigação através de histórias de vida. Lisboa: Ela por ela, 2012. p. 12

9. Ibidem. p. 9-10 a questão foi elaborada no Fale Conosco do seguinte modo:

O objetivo deste blog é criar um ambiente acolhedor para dividir histórias sobre este tema tão difícil, sobre o qual não nos sentimos, muitas vezes, confortáveis para falar a respeito. E para dizer que, apesar de tudo, Somos Amadas. Se essas narrativas literárias e depoimentos fizerem você lembrar, e não só isso, impulsionarem você a escrever e compartilhar memórias escreva para nós. Estamos prontas para quebrar o silêncio pelo e-mail [...]. 
Já os depoimentos produzidos oralmente foram tratados em forma de questões específicas sobre a temática, como as que se podem ler a seguir: como você vê a violência contra meninas e mulheres em contextos de fundamentalismo religioso? Qual a sua denominação religiosa? Quanto tempo você participou? Você ainda participa? Como era a atuação da sua família? Sua família ainda é religiosa? Como você se vê, hoje, em relação à sua experiência religiosa?

Assim sendo, no segundo momento da pesquisa, optamos por não ter um roteiro com perguntas, à medida que procurávamos as singularidades das experiências e das subjetividades de cada narradora, colocando em primeiro plano sua vida, a partir da seguinte colocação: "Imagine que você pudesse realizar um filme da sua vida. Que momento, espaços e personagens você escolheria e por quê??" Ou ainda: "Se você escrevesse um livro sobre sua vida, com qual momento da sua vida começaria, que espaços e personagens você escolheria e por quê??".

Por essa razão, existe uma diferença significativa entre o conteúdo das histórias de vida recolhidas antes e depois do contato com as ideias de Magalhães, uma vez que, nas primeiras recolhas, somente nos preocupamos com as questões específicas sobre a problemática da pesquisa. Esse deslocamento teórico-metodológico, certamente, trouxe uma mudança potente no resultado das análises, conforme poderá ser observado mais à frente.

\section{O BLOG E O MICROBLOG (TWITTER) COMO INSTRUMENTOS DE PESQUISA E DE REGISTRO EM HISTÓRIA DE VIDA}

Existem várias técnicas que podem ser utilizadas na investigação em Histórias de Vida: entrevistas semiestruturadas, entrevistas abertas, diálogos abertos, dentre outras, inclusive, solicitando à pessoa que escreva. Em nossa pesquisa, criamos um blog para que as pessoas interessadas escrevessem suas histórias. O blog teve suas características próprias, aspecto inerente a um weblog. Nele, priorizamos a entrada dos conteúdos em ordem cronológica; a hipertextualidade; a multimidialidade; a informalidade; o microconteúdo e a atualização frequente ${ }^{10}$. Ele pode ser classificado como um blog temático, uma vez que tinha como prioridade a pesquisa acadêmica. Foi criado na plataforma Wordpress e constitui-se, predominantemente, de textos escritos, embora tenham sido incluídas também outras linguagens. Nesse sentido, ele pode ser classificado como um blog funcional ${ }^{11}$, servindo como dispositivo para a produção e o compartilhamento das narrativas pessoais.

Fragmentos dessas histórias, tanto escritas como orais, foram tornados públicos no blog ${ }^{12}$ (Figura 1), sendo este claramente identificado como espaço de pesquisa acadêmica. Associado ao Twitter, o blog constituiu-se também como um instrumento de reflexão e debate sobre a temática da pesquisa.
10.ZAGO, Gabriela da Silva. Dos blogs aos microblogs: aspectos históricos, formatos e características. In: CONGRESSO NACIONAL DE HISTÓRIA DA MÍDIA, 6., 2008, Niterói. Anais [...]. Niterói: UFRGS, 2008. Disponível em: http://www. bocc.ubi.pt/pag/zago-gabriela-dos-blogs-aos-microblogs.pdf. Acesso em: 30 abr. 2020.

11. AMARAL, Adriana; RECUERO, Raquel; MONTARDO, Sandra. Blogs: Mapeando um objeto. In: AMARAL, Adriana; RECUERO, Raquel; MONTARDO, Sandra (org.). Blogs.com: estudos sobre blogs e comunicação. São Paulo: Momento, 2009. p. 27-54.

12. Disponível em: https:// somosamadas.wordpress. com. 
comunicação \& educação • Ano XXVI • número 1 • jan/jun 2021

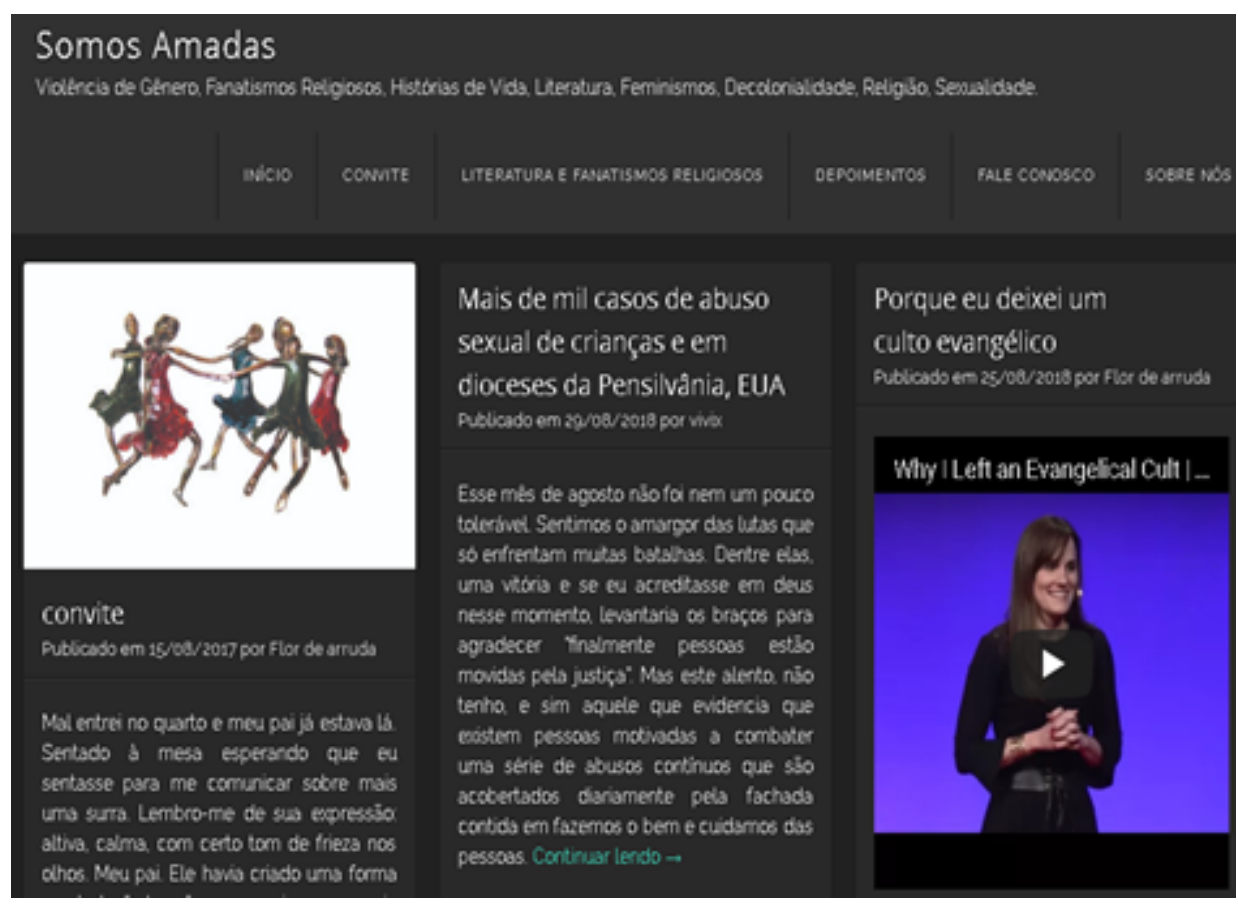

Figura 1: Blog Somos Amadas

Fonte: Elaborado pela autora (2019).

Ao longo da investigação, 15 histórias foram contadas por leitores do blog, sendo 13 delas histórias de mulheres fizeram, efetivamente, parte do corpus. Os critérios de exclusão de duas histórias foram: (1) não se caracterizar como história de vida, sendo um relato episódico sobre a questão de gênero e sexualidade, ocorrido durante um curso de formação para professores; (2) tratar-se da história de violência sofrida em contexto religioso por um menino, hoje adulto, em seu processo de constituição como sujeito homossexual.

Quando o blog contava com três meses de existência, tínhamos recebido somente uma história, por isso organizamos algumas estratégias de divulgação. Primeiramente, criamos um cartão para entregar, de mão em mão, em dois eventos acadêmicos em novembro de 2017: (1) $3^{\circ}$ Simpósio Sul da Associação Brasileira de Religião (ABHR): Educação, Religião e respeito às diversidades, na Universidade Federal de Santa Catarina (UFSC), no qual organizamos e participamos da mesa "Violência contra Meninas e Mulheres em Contextos Religiosos e o papel da Educação"; (2) VI Seminário de Pesquisa promovido pelo Núcleo Infância, Comunicação, Cultura e Arte (PPGE/CNPq/UFSC), do Centro de Ciências de Educação da UFSC, no qual proferimos a palestra Infância, Cultura e Fundamentalismos Religiosos. Além da entrega dos cartões, fixamos um tópico sobre o blog no Twiter. Assim, quem lá entrava tinha a possibilidade de conhecer e compartilhar sua história.

Após essa ação, passamos de uma história para dez, das quais selecionamos oito. As cinco histórias que completaram as treze que fizeram parte da 
pesquisa foram recolhidas, presencialmente, em regiões e locais com dias e horas marcados. As cinco depoentes souberam da pesquisa por pessoas que a divulgaram, foram apresentadas ao blog, porém, preferiram contar suas histórias oralmente, as quais foram gravadas em áudio.

No sentido de organizar as informações provenientes das narrativas das participantes, optamos pela elaboração de uma categorização temática (segundo a análise de conteúdo proposta por Bardin ${ }^{13}$, que, consequentemente, delinearam-se como categorias de análise. As categorias foram aplicadas ao material empírico, no entanto, não são, necessariamente, extraídas dele, embora surjam do confronto com esse material.

Há, como será possível observar, uma significativa diferença entre a Tabela 1 e a Tabela 2, pela especificidade de dois momentos da pesquisa sobre os quais já nos referimos anteriormente e, como consequência, resultam daí as categorias iniciais, conforme a Tabela 1. Já na Tabela 2, optamos por deixar as categorias relativas às memórias sobre infância e adolescência e integrar as demais na parte da apresentação das biografadas. Reaproveitando o potencial das demais, procedemos algumas modificações, quer a nível pontual, quer a nível estrutural. Note-se, por exemplo, que a categoria Família, na Tabela 1, passou a compor a categoria Religião, Família e Política, na Tabela 2.

\begin{tabular}{|c|c|}
\hline Categorias & Subcategorias \\
\hline \multicolumn{2}{|l|}{ Apresentação das biografadas } \\
\hline Memórias sobre a infância & $\begin{array}{l}\text { 2.1 Percepção da infância em contexto religioso } \\
\text { 2.2 Percurso escolar } \\
\text { 2.3 Relações familiares e sociais durante o período } \\
\text { da infância }\end{array}$ \\
\hline Memórias sobre a adolescência & $\begin{array}{l}\text { 3.1 Percepção da adolescência em contexto religioso } \\
\text { 3.2 Percurso escolar } \\
\text { 3.3 Percepção das escolas que frequentou no período } \\
\text { da infância e adolescência }\end{array}$ \\
\hline Percepção sobre a fase adulta & 4.1 A realização dos sonhos da infância na fase adulta \\
\hline Família & $\begin{array}{l}\text { 5.1 Ambiente familiar } \\
\text { 5.2 Participação da família na religião }\end{array}$ \\
\hline
\end{tabular}

Fonte: Produção da autora (2019)

13. BARDIN, Laurence. Análise de conteúdo. São Paulo: Edições 70, 2011. 
14. Imagine que você pudesse realizar um filme da sua vida. Que momento, espaços e personagens você escolheria e por quê? Ou ainda: Se você escrevesse um livro sobre sua vida, com qual momento da sua vida começaria, que espaços e personagens você escolheria e por quê?

15. MAGALHÃES, Maria José. op. cit., 2012.

\section{Tabela 2: Categorização Final: $2^{\circ}$ momento da pesquisa com questão aberta ${ }^{14}$}

\begin{tabular}{|c|c|}
\hline Categorias & \multirow{2}{*}{ Subcategorias } \\
\hline Apresentação das biografadas & \\
\hline Religião e abuso espiritual & $\begin{array}{l}\text { 2.1 Ponto de vista sobre a religião e as violências em } \\
\text { seu contexto } \\
\text { 2.2 Percepção sobre as manipulações } \\
\text { 2.3 Manipulações pelo medo } \\
\text { 2.4 Momento(s) de vivência/convivência com o medo } \\
\text { 2.5 Pontos de vista sobre religião } \\
\text { 2.6 Percepção sobre a diferenciação de gênero nas } \\
\text { violências em contextos religiosos }\end{array}$ \\
\hline Fundamentalismo Cristão & $\begin{array}{l}\text { 3.1 Doutrinação na pequena infância } \\
\text { 3.2 Percepção sobre os métodos de persuasão e } \\
\text { doutrinação } \\
\text { 3.3 A criança-soldado } \\
\text { 3.4 Doutrinação de crianças: o horror ao outro }\end{array}$ \\
\hline Síndrome do Trauma Religioso & $\begin{array}{l}\text { 4.1 Doenças psíquicas } \\
\text { 4.2 Percepção sobre transtornos mentais na idade adulta }\end{array}$ \\
\hline Direitos da Criança & $\begin{array}{l}\text { 5.1 Percepção sobre fundamentalismos religiosos e } \\
\text { Direitos da Criança } \\
\text { 5.2 Maus-tratos infantis } \\
\text { 5.3 Posicionamentos frente à problemática dos maus- } \\
\text { tratos infantis }\end{array}$ \\
\hline Direitos das mulheres & $\begin{array}{l}\text { 6.1 Percepção sobre fundamentalismo religioso e } \\
\text { opressão das mulheres } \\
\text { 6.2 Percepção da resistência das mulheres frente aos } \\
\text { atos de violências fundamentalistas } \\
\text { 6.3 Participação pessoal no contexto da resistência às } \\
\text { violências contra meninas e mulheres nos contextos } \\
\text { religiosos }\end{array}$ \\
\hline Religião, família e política & $\begin{array}{l}\text { 7.1 Percepção sobre a existência dos fundamentalismos } \\
\text { e sua relação com diversos grupos políticos que usam a } \\
\text { religiosidade na tentativa de ganhar poder } \\
\text { 7.2 Percepção sobre o assédio espiritual } \\
\text { 7.3 Percepção sobre articulação entre a religião com } \\
\text { outras dimensões, desde a familiar à política. }\end{array}$ \\
\hline Identidade e sentido de pertença & $\begin{array}{l}\text { 8.1 Percepção sobre a Identidade } \\
\text { 8.2 Construção da Identidade } \\
\text { 8.3 Momento marcante no processo de Identidade }\end{array}$ \\
\hline
\end{tabular}

Fonte: Produção da autora (2019).

\section{DELINEAMENTOS POR MEIO DE HISTÓRIAS DE VIDA}

Entre agosto de 2017 e agosto de 2018, recolhemos as histórias das biografadas, das quais selecionamos treze. Dessas 13 mulheres, seis contaram suas histórias pela própria $\mathrm{voz}^{15}$, seis focaram exclusivamente a temática religiosa a partir de questões específicas elaboradas pela pesquisadora sobre o fundamentalismo religioso e uma delas escreveu sua história-artística-de-vida. 
Das 13 mulheres, dez nasceram em contextos de fundamentalismo religioso, duas entraram em um desses contextos no final da infância e uma, na adolescência. Quase a totalidade delas veio de contextos cristãos: sete vieram de igrejas pentecostais clássicas, duas de igrejas neopentecostais, uma da igreja católica, uma fazia parte do grupo das Testemunhas de Jeová e uma era de origem islâmica. Nove depoentes haviam rompido com suas religiões.

Em relação à violência sexual, quatro das narradoras foram vítimas de violência sexual: duas delas no próprio contexto religioso, uma no contexto familiar, e uma em outro contexto urbano. Seis delas contaram ter sido vítimas de castigos físicos infligidos pelos pais, mais especificamente surras em consequência da doutrinação religiosa.

Seis delas são negras e, entre elas, cinco são provenientes de famílias anteriormente ligadas a religiões afro-brasileiras: umbandistas. Duas participantes denominaram-se bissexuais e estão em relacionamentos estáveis com mulheres.

Sobre a questão específica da produção de uma história-artística-de-vida, Wadi mostra seu trabalho com histórias de vida de mulheres palestinas. Em seus estudos, a autora defende que "a melhor forma para criar ligações e alianças com o Ocidente será aproximar-se dos valores culturais e políticos ocidentais" ${ }^{\prime 16}$. Para ela, o que impede a memória de culturas do Sul, como a palestina, de tornarem-se públicas são as nações poderosas que não as querem ouvir, a falta de um público para ouvi-las. Nesse sentido, utilizar as artes, como o cinema, as artes plásticas, a literatura, dentre outras, é das formas dessas possíveis ligações e alianças, uma vez que a arte é uma "voz" que pode ser mais ouvida do que outras formas mais silenciosas e silenciadas ${ }^{17}$. Nessa perspectiva, a autora defende que as histórias-artísticas-de-vida têm uma abrangência maior que as histórias de vida em narrativa tradicional, as quais também podem se caracterizar como escrevivências.

\section{ANÁLISE DOS(AS) SEGUIDORES(AS) DO TWITTER}

O blog da pesquisa foi divulgado pelo Twitter com o apoio de perfis de grupos e influenciadoras feministas. $\mathrm{O}$ impulsionamento foi dado pelos perfis @blogueirasfeministas, @ naomecalo e @lolaescrevalola, que compartilharam um conteúdo inicial. Em 21 de outubro de 2018, fizemos uma análise dos seguidores nesse período de divulgação pela mídia social de microblogging com o perfil do referido blog.

De acordo com o relatório dessa data, o microblog possuía 306 seguidores, o público era majoritariamente feminino, com $72 \%$ que se denominavam mulheres. E $28 \%$ dos perfis eram masculinos. Descobrimos uma maioria massiva de adolescentes mulheres, 111, ao lado de 48 mulheres adultas. Dentre os perfis, 43 se denominaram mulheres negras. É significativo que 90 destes perfis se intitularam feministas. Apenas 13 mulheres alegaram ter religião, dentre elas: cristãs (7), budistas (2), espíritas (1), umbandistas (1) e misticismos/Wicca (1).

16. WADI, Shahd. O ser das mulheres palestinas: histórias de vida entre cusquices e rabiscos. In: MA GALHÃES, Maria José. et al. Pelo fio se vai à meada: percursos de investigação através de histórias de vida. Lisboa: Ela por ela, 2012. p. 130.

17. Ibidem 
Desse modo, o perfil do referido blog alcançou, mensalmente, 2 mil pessoas que se interessaram sobre a temática, de acordo com relatórios dos últimos meses que antecederam o encerramento da pesquisa: agosto de 2017 a agosto de 2018.

Embora o foco deste artigo seja o uso do blog e do microblog no contexto da pesquisa, podemos fazer uma breve referência às conclusões mais gerais sobre a referida investigação. A pesquisa constatou que, dos movimentos que se desenvolveram nas três religiões monoteístas: judaísmo, cristianismo e islamismo, o movimento cristão ainda é um dos que tem maior representatividade nessa investigação. Nele, o abuso espiritual, que se dá por meio de Manipulações é o maior responsável pelas demais formas de violências contra meninas e mulheres nos contextos de fundamentalismos religiosos, e a pouca visibilidade do tema nas discussões acadêmicas e na educação em geral são contributos para a recorrência dos casos e para a perpetuação do abuso espiritual.

Winell assinala, com clareza, que as manipulações funcionam como "mecanismos de controle da mente"18. E é nesse campo que a pesquisa chama a atenção para o perigo da doutrinação na pequena infância (0 a 6 anos de idade). Segundo Winell ${ }^{19}$, as consequências da doutrinação religiosa são infinitamente mais danosas quando a criança nasce em contexto de fundamentalismo religioso. Para ela, os pais juntam-se às igrejas para induzirem as crianças (desde o engatinhar) aos sistemas de crenças, e as estratégias utilizadas para doutrinar essas crianças indicam a profundidade do medo e da ansiedade que elas desenvolverão e o quanto esses dois aspectos estão interligados. Uma das questões para as quais a autora chama a atenção é o ataque à imaginação das crianças, já que a técnica mais poderosa do fundamentalismo (no caso que ela estuda, o cristão) é uma tática do terror, e sabemos o quanto o medo pode paralisar as forças imaginantes.

Ao discutir a questão da doutrinação de crianças, Winell chama a atenção para as religiões rígidas, cuja origem remete ao fundamentalismo cristão. Mais do que olhar para os aspectos históricos dessas religiões, a autora convida-nos a olhar para os métodos de persuasão que são reconhecidamente poderosos para o recrutamento e a retenção de seus membros. Aliados aos métodos, ela aponta alguns artefatos culturais, como livros, discos, hinários, programas ("infantis"?), que têm como objetivo manipular mental e emocionalmente os adeptos, desde a pequena infância.

Todas as questões consideradas acima foram essenciais para pensarmos qual o papel da educação nesse contexto. Poderíamos dizer que a pesquisa mostrou que a educação e o fundamentalismo cristão encontram-se naquilo que denominamos como pedagogia do medo. Dessa forma, regulam-se vontades de liberdade, mata-se a curiosidade, a imaginação, o desejo pela novidade, aspectos essenciais do espírito inquieto e criador, tão importantes na formação da criança. 


\section{COMUNICAÇÃO DA CIBERCULTURA A SERVIÇO DAS PESQUISAS EM EDUCAÇÃO}

Devido a situarmo-nos no campo das Ciências Humanas e Sociais, cabe destacar que, na perspectiva de pesquisa em Histórias de Vida que adotamos, fazendo o uso de ferramentas de comunicação da cibercultura ${ }^{20}$, não se objetiva ressaltar a excelência dos instrumentos, ou seja, não temos como finalidade pesquisar o que as ferramentas podem fazer, nem por que elas fazem o que fazem, mas sim como podemos trabalhar com elas no sentido de ampliar a possibilidade das mulheres, assim como de outros grupos silenciados, soltarem suas vozes, bem como abrirem espaço para que essas vozes possam ser ouvidas por mais gente.

Nesse sentido, ao valermo-nos de ferramentas de comunicação digital associadas às metodologias e à pesquisa em educação, deslocamos o foco dos atributos técnicos dos instrumentos para a possibilidade cultural que oferecem aos pesquisadores e participantes das pesquisas, de organizar, recolher, divulgar as práticas das vozes. Para nós, o aspecto central da investigação está na perspectiva de melhor elaborar e compreender o que acontece entre as vozes, nas relações, e como essas vozes interagem entre si nas relações que compõem tais práticas.

Assim, o que tentamos dizer é que as tarefas propostas para as metodologias de pesquisa em educação podem revelar-se plenas de desafios, exigindo dos pesquisadores a experimentação com instrumentos teórico-metodológicos que os habilitem a lidar com situações novas e tão mais complexas quanto mais complexo for se tornando o corpo social. E a invenção de espaços de interpelação sensível e de autoria compartilhada, a partir de estruturas técnico-culturais como os blogs e microblogs, parece ser uma forma de experimentação metodológica sintonizada a esse tipo de desafio.

\section{CONSIDERAÇÕES FINAIS}

No âmbito das pesquisas científicas e acadêmicas, há que se considerar as inovações tecnológicas como potenciais aliadas do/a pesquisador/a. No caso deste trabalho, nossa atenção voltou-se ao potencial dos blogs e microblogs na criação de procedimentos de pesquisa.

Considerando os objetivos da investigação da qual se origina este texto, tais ferramentas foram determinantes como forma de aproximação e registro para fazer emergir as histórias de meninas e mulheres que sofreram algum tipo de violência em contextos de fundamentalismos religiosos. A metodologia de Histórias de Vida, associada ao espaço de intimidade e segurança oferecido pelo blog e pela possibilidade de dialogar com pessoas que viveram experiências semelhantes por meio dos processos de publicação das plataformas, favoreceu não somente o acesso às formas de violências praticadas no contexto examinado,
20. LEMOS, André. Cibercultura: alguns pontos para entender a nossa época. In: LEMOS, André; CUNHA, Paulo (org.). Olhares sobre a cibercultura. Porto Alegre: Sulina, 2003. p. 11-23. 
mas também a possibilidade de refletir coletivamente sobre como acontecem tais formas de violências.

A necessidade de aliar ao blog um microblog, o Twitter, revelou-se durante o processo da pesquisa, uma vez que, por meio dessa ferramenta de comunicação, tornaram-se possíveis muitas outras manifestações sobre a temática, bem como o encontro entre pessoas, incluindo outros pesquisadores que se interessavam pelo tema. Nesses encontros, os tweets contendo dicas de leitura, filmes, trabalhos acadêmicos, dentre outras indicações relevantes à pesquisa, foram possíveis em virtude da própria especificidade da ferramenta.

Dos resultados obtidos nas análises dos posts, destaca-se o fato de o Twitter servir como elemento potencializador quando colocado em função do blog. Entretanto, diferentemente do blog, o Twitter, além de publicações livres, como ocorre com os blogs, destacou-se como ferramenta de comunicação direta entre perfis, incentivando a participação e o compartilhamento de informações que geram conhecimento, além de caracterizar-se como ferramenta de comunicação para as pessoas acompanharem umas às outras a distância.

\section{REFERÊNCIAS}

AMARAL, Adriana; RECUERO, Raquel; MONTARDO, Sandra. Blogs: mapeando um objeto. In: AMARAL, Adriana; RECUERO, Raquel; MONTARDO, Sandra (org.). Blogs.com: estudos sobre blogs e comunicação. São Paulo: Momento Editorial, 2009. p. 27-54.

ARMSTRONG, Karen. Em nome de Deus: o fundamentalismo no Judaísmo, no Cristianismo e no Islamismo. São Paulo: Companhia das Letras, 2009.

BARDIN, Laurence. Análise de conteúdo. São Paulo: Edições 70, 2011.

EVARISTO, Conceição. Minha escrita é contaminada pela condição de mulher negra. In: LIMA, Juliana Domingos de. Jornal Nexo, São Paulo, 2017. Disponível em: https:/ /bit.ly/2HVfnIW. Acesso em: 30 abr. 2020.

LEMOS, André. Cibercultura: alguns pontos para entender a nossa época. In: LEMOS, André; CUNHA, Paulo (org.). Olhares sobre a cibercultura. Porto Alegre: Sulina, 2003. p. 11-23.

MAGALHÃES, Maria José. Construção do sujeito mulheres: subjetividades das vozes e dos silêncios. In: MAGALHÃES, Maria José et al. (org.). Pelo fio se vai à meada: percursos de investigação através de histórias de vida. Lisboa: Ela por ela, 2012. p. 9-12.

SANTOS, Boaventura de Sousa. Pela Mão de Alice: o social e o político na pós-modernidade. 4. ed. São Paulo: Cortez, 1997.

SKLIAR, Carlos Bernardo; DUSCHATZKY, Sílvia. O nome dos outros: narrando a alteridade na cultura e na educação. In: LARROSA, Jorge; SKLIAR, Carlos 
(org.). Habitantes de Babel: políticas e poéticas na diferença. Belo Horizonte: Autêntica, 2001. p. 119-138.

WADI, Shahd. O ser das mulheres palestinas: histórias de vida entre cusquices e rabiscos. In: MAGALHÃES, Maria José et al. Pelo fio se vai à meada: percursos de investigação através de histórias de vida. Lisboa: Ela por ela, 2012. p. 113-133.

WINELL, Marlene. Leaving the Fold: a guide for former fundamentalists and others leaving their religion. Berkeley, CA: New Harbinger Publications, 2007. ZAGO, Gabriela da Silva. Dos blogs aos microblogs: aspectos históricos, formatos e características. In: CONGRESSO NACIONAL DE HISTÓRIA DA MÍDIA, 6. 2008, Niterói. Anais [...]. Niterói: UFRGS, 2008. Disponível em: http:/ /www.bocc. ubi.pt/pag/zago-gabriela-dos-blogs-aos-microblogs.pdf. Acesso em: 30 abr. 2020. 